\title{
Discussion to the paper by A. M. Connell
}

\section{Chairman: Professor J. C. Goligher}

WatkInson. I'd like to congratulate Dr Connell for never saying the words 'mucous colitis' in the whole of this $30 \mathrm{~min}$. These pernicious words should be ceremoniously buried. I have seen at least three patients who have been physiologically ruined by being told they had mucous colitis and they've lived from week to week in dread of colectomy. A simple explanation of irritable colon as a diagnosis turned these anxious people into normal people.

SiNGH. There are two views about irritable colon, both from Oxford, that in some cases at least this leads to ulcerative colitis and secondly that it can progress to diverticular disease. Do you believe this?

ConNell. Well, I haven't seen this condition, as I've defined it, go on to ulcerative colitis. I have seen these patients with ulcerative colitis present with the symptoms of irritable colon. As far as the progression to diverticular disease I would rather not reply to this because I think Mr Parks who will be speaking to us later on is going to be dealing with this point.

HADLEY. I think I'd present it in a negative way and say that in ulcerative colitis it is in the first attack unusual for the patient ever to have had any bowel symptoms before, he may have done but this is unusual. I agree with Dr Connell in the latter respect, that this doesn't lead usually to ulcerative colitis.

Strachan. About this business of post-dysentery colitis: I'm not quite sure that we can always be very happy after amoebic dysentery that we have got rid of the disease. A personal experience might be an example. I was checked a couple of times both in Edinburgh and at Preston after the war. I had it during the war. I still had this irritable colon which lasted about 3 years and was a damned nuisance. So after convalescing from another disease I persuaded my physician to give me EBI and emetine, and I got rid of the symptoms. Whether this was psychosomatic or what I don't know but it certainly cleared up the symptoms.

ConNell. I agree entirely with this, I hope I was careful to point out that this was just a consideration we had to have but this irritable colon did frequently follow an atrack of acure amoebic colitis, and in the Middle East particularly one will find these people with an irritable bowel in this sense, who are still passing amoebic cysts but no vegetative forms. So all I suggest is this, that it may well be that these people have some focus of irritability left in the bowel; it may be that they have nests of amoebae. As far as I know, no one has described pathological changes which would account for this recurring symptomatology.

Misiewicz. One of the troubles of diagnosing irritable bowel syndrome I would say is that there are no, or few, positive findings and that the diagnosis is largely one of exclusion. I would like to ask Dr Connell if he would agree that there are some positive findings of real value in the clinical diagnosis of this condition. One is that the sigmoid colon is very often not only palpable but also tender. Second, that if you take careful history of the bowel habits you often find than the actual shape of the stool gives you a clue about the abnormal muscular activity with moulding of the stoolo The third point is that on sigmoidoscopy, during the passage of the instrument through the sigmoid ben you can quite often reproduce exactly the patient's pain by distension. These are three points of clinica value.

ConNell. Well, I'd agree of course, with this, but $\dot{I}$ deliberately underplayed it for this very good reason: that all these things you've mentioned can occur with some frequency in a normal subject. You can have a part of the colon palpable which, if you press hard enough, the patient will say that it is tender. You can

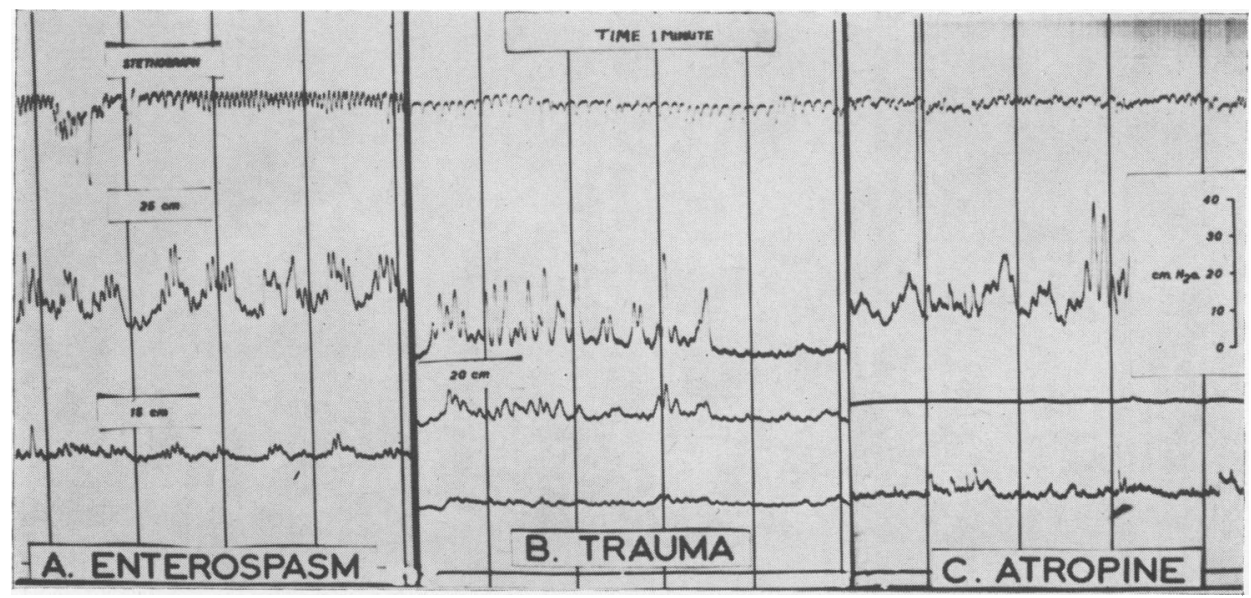


have this radiological appearance in a normal subject, you can reproduce pain such as the patient feels he's had, by sigmoidoscopy and so on. But there's this enormous overlap between the normal and the irritable colon, just as these increased pressures occur more frequently in the irritable colon than in the normal subject, but they are not exclusively signs of irritable colon.

Question. Dr Connell referred to this question of atropine producing a fast wave pattern. Is there any information about atropine or probanthine being contraindicated in a condition such as colitis in which one wishes to damp down rather than to potentiate muscle activity? I realize that in the small bowel one aften uses probanthine and it may be justifiable there but should probanthine be used if you suspect large have bowel spasm too?

ConNell. The graph shown (p. 672) refers to this problem of atropine. Atropine may be unusual in this, I cannot speak for probanthine because I haven't studied it, have you, Dr Misiewicz?

MisIEWICZ. It certainly knocks down the activity of the colon when it is used by intravenous injection. But I don't think anyone else has shown any objective alimentary effect in ordinary medication.

Connell. This is an old graph, excuse the term enterospasm which was used at this time, this is the fast wave pattern we have in one such patient. Ignore this just now. Here is a part of a record from atropine, which again shows these spiky waves. If you use atropine, in a normal therapeutic dose, this was $6 \mathrm{mg}$ intravenously, this is the sort of thing you get. If you push the dose up then you will knock out all activity in the colon. I suspect probanthine is something the same, although I cannot speak personally for it. And clinically of course, if you push atropine or belladonna type products or probanthine to the limit of side effects, you will affect colonic motility. But whether you should use it or not I think has to be judged at the moment on clinical evidence rather than this.

AVERY JONES. I have seen probanthine given subcutaneously in a severe case, with very successful results, and I think that this is one therapeutic possibility. The use of antidepressive therapy too, in some cases is another line of treatment. I would like to confirm that this is a very real clinical syndrome and it is not only the wide spectrum of severity which sometimes makes it a little difficult for some people to accept. But it does include some very severe cases with recurrent pain. I think I recognized one of Dr Connell's cases who had a laparotomy, nothing was found, his symptoms subsequently subsided when he gave up smoking. I think that is another therapeutic measure, I think it is a common disease.

ChaIRman. I think what Dr Avery Jones says is true, particularly for physicians. If I may address myself to the surgeons of the audience, I would say that I think their job is to be the custodians of organic disease, and to regard this diagnosis with the utmost suspicion always. And accept it only after the most searching reinvestigation and re-examination. Leave this syndrome to the physicians please. 